\title{
Accounting for Purposive Social Action
}

Nick Bloom

Duke University

September 2016

\begin{abstract}
This paper articulates a sociological approach to analyzing individual choices. I discuss sociological roadblocks to economic thinking, namely disagreements about preference formation, social influence, and the importance of group-level phenomena. I show that these ideas can be integrated into an individual choice modeling approach based on the assumption that individuals maximize the "morality" or "rightness" of a choice in a particular context, rather than its rational utility. Asking scholars to place explicit constraints on the analysis itself, rather than on the cognition of the actors being analyzed, allows for truly scientific, endogenous models of individual choice that maintain analytical rigor. I conclude by elaborating several tools for methodological implementation of the model.
\end{abstract}

But with a few exceptions, economists and political scientists typically pay little attention to the structure of preferences, while sociologists and anthropologists do not embed their analyses of social forces and culture ina powerful analytical framework.

- @Becker1996, 3

Individual choices lie at the heart of most social phenomena. A neglect of individual choice, then, renders sociological explanation unnecessarily handicapped. Despite strong initial attempts (Parsons and Shils 1951), and a repeated insistence that individual choices are influenced by social networks and supra-individual groups(Granovetter 1985; DiMaggio 1988; Friedkin and Cook 1990; Powell and DiMaggio 1991; Pescosolido 1992; Christakis and Fowler 2007, 2008; Liu, King, and Bearman 2010), sociology has failed to produce any viable, analytically-rigorous alternatives to standard economic rational-choice models of individual decision-making. In fact, the only programmatic statement on modeling individual choice in a sociology journal is by an economist (Durlauf 2001).

This paper outlines a rigorous, sociological model of individual choices. My central argument is that sociologists should think of individuals as making choices that maximize their idiosyncratic standard of morality, or "reasonable-ness," in a given context. I set individual standards of morality as a function of time, social influences and material resources. I 
also argue that analysts can bound the potentially endless number of confounding variables in an endogenous choice approach by making analytical results conditional on the choice context. This approach to conditionality departs from previous sociological approaches, which make individual cognition dependent on the context (Swidler 1986, 2003), and the countervailing economic approach, which uses constraints on individual cognition to minimize the influence of the choice context (Stigler and Becker 1977).

In my elaboration of the approach, I leave certain things aside. First, I do not discuss the historical reasons for sociology's neglect of individual choice modeling, instead proceeding as if modeling individual choices is something contemporary sociologists want to do. Second, I also depart from the many suggestions contained in past charters for economic sociology (Granovetter 1985; Zelizer 1988, 2012; Swedberg and Granovetter 1991, Introduction; Callon 1998; Krippner 2002; Krippner and Alvarez 2007). This is not to downplay the importance of these works, as the critiques and ideas in this paper are partially or wholly indebted to those thinkers. Instead, I merely recognize that these scholars suggest altogether different approaches than the one advanced here. I attempt to develop an approach that incorporates their concerns and arguments, but also recognize that analytical rigor is mutually exclusive to holistic integration. Finally, the proposals and framing of the paper were borne from a serious consideration about the reasons for general sociological avoidance of choice modeling. As the epigraph to the paper notes, the deficiency of choice modeling in sociology is less because the discipline maintains assumptions that are incompatible with an analytically rigorous approach, and more because it has elided analytical rigor itself. I therefore lay out an approach that integrates choice modeling into sociology while leaving the majority of existing disciplinary assumptions intact. As such, the theoretical contributions of this paper are more a tint than a new palette.

The paper has two main parts. In the first, I summarize core principles of economic thinking and foreshadow sociological criticisms of the economic approach. I then lay out the theoretical preconditions for sociological choice modeling, which I do through an extensive survey of existing sociological work. The second section formalizes the theoretical discussion in the first section. I begin with the economic utility model, and build through endogenous choices up to the incorporation of hierarchical group-level outcomes.

\section{ECONOMIC THINKING AND INDIVIDUAL CHOICE}

A graduate microeconomics textbook begins its chapter on choice by reminding students that "economics is about action" (Rubinstein 2012:23). In other words, to be an economist means to adhere to a particular way of thinking about and modeling human action. This way of thinking places scope conditions on the cognition and motivatiob of the actors being 
analyzed. This section describes the basic tenets of the economic perspective on motivation, choice and action.

Note: I rely heavily on Ariel Rubinstein's (2012) graduate-level introductory microeceonomics textbook for explication on the ideas in this section. A discipline's fundamental tenets are often most accessible through its introductory textbooks. This is particularly true for microeconomics, which has largely operated under the same analytical assumptions for many decades (Stigler and Becker 1977). I chose Rubinstein's textbook because of its economic irrationality: it is open-source, and thus easy to obtain, but is also much higher quality than its lack of price implies. Where available, I cite relevant supporting or original statements by economic thinkers.

\section{Preferences, Utility, and Rationality}

Preferences are the foundation of economic thinking about action. Economists assume that all individuals have preferences (about basically everything), and generally assume that the source of these preferences is of little interest or relevance (Stigler and Becker 1977; c.f., Becker 1996). In other words, economists think of preferences as "exogenous" to the choosing context (meaning their causal source is external to the choice situation such that it is unrelated to it). Preferences are, consequently, idiosyncratic, and not based on the actions or preferences of others. Together, an individual's preferences can be represented as a mathematical function of "utility." Utility is simply the quality that is maximized over a given, bounded preference set. Utility is often money in economic analyses, but it is just as often not (Becker 1993). Money simply makes a convenient stand-in for utility because it is continuous over the real line; discrete outcomes required some Nobel Prize-worthy work to incorporate (Domencich and McFadden 1975).

Preferences alone are not enough for action; they are akin to a car without an engine. In economics, rationality is the cognitive "engine" pushing preferences "car" toward outcomes. Rationality in economics simply means the joint truth of two things:

1. Each individual has a complete, transitive set of all of their preferences (represented as a Utility function $\mathrm{U}$ )

2. Individuals choose the outcome in a given situation that corresponds to the maximum value of that particular utility function.

In short, economic actors are rational because their choices maximize their idiosyncratic utility functions. Economic actors maximize self-interest, but it is a bit oversimplified to

\footnotetext{
${ }^{1}$ Durlauf (2001) says that individuals are rational when "when their beliefs given [the choice set], as represented by subjective conditional probabilities, are confirmed by the actual conditional probabilities which arise in the environment under study" (58).
} 
call rational actors selfish. Rational actors are selfish in a narrow sense, in that their own exogenous preferences are their only evaluative standard, but self-interest can guide them in a number of possible directions (Becker 1993). However, the assumed self-interest of actors, coupled with the idiosyncracy of preferences, does place limits on the kinds of explanations available to economists. For example, current economic attempts to explain social phenomena, like social influence and charitable giving, incorporate these ideas into a self-interested framework. As I will discuss, it is at these moments that economic analysis shows rare contradiction and ineptitude. 2

A series of critiques to the rational model in the 1980s led a group of economists to broaden their views of preferences and to take actual human behavior into account (Tversky and Kahneman 1981; Kahneman, Knetsch, and Thaler 1991). "Behavioral" economists broadened utility to incorporate attitudes not just about the rank-ordering of various outcomes, but also attitudes about the outcomes themselves. The behavioral approach also incorporates many other psychological theories about cognition, framing, situational pressures, and bias (e.g., Ariely 2008). For example, an individual deciding which treatment to pursue after being diagnosed with a terminal illness may be biased toward avoiding the worst case (i.e. death), and thus maximize his or her preferences by choosing any alternative (Hough 2013). In another scenario, an individual may prefer sweets and fats, but may be pursuaded to choose a different option because it has been framed as a healthy, environmentally-friendly choice (Just and Payne 2009). Behavioral economics has certainly gained popularity over the past few decades (and its originators have won Nobel Prizes), but it remains in a fringe position with respect to economics. Few economics departments employ behavioral economists, and the mainstream discipline proceeds according to rational, utility-maximizing assumptions.

\section{Consequences of Rationality: Equilibrium}

In addition to constraints on cognition, economists have expectations about aggregate effects in the systems they model. In general, economists expect systems to converge on equilibrium, whether these systems are collections of cognitive impulses in an individual, individual choices in a market, or different markets in a national economy. At the micro level, equlibrium can be stated simply as the circumstance wherein agent $a$ has no desire to move away from his choice $c$ for all agents $A$. This statement is conditional on the choices, meaning that the real limit of each individual's own preferences might not be maximized (e.g., a consumer might prefer a free Toyota), but that all preferences are as close to that maximization as possible given the choices available (e.g., cars almost always cost money).

\footnotetext{
${ }^{2}$ Consider, for example, Gary Becker's (1996) attempt to explain church attendance (237-238)
} 
Equilibrium makes sense in product markets, when prices are expected to converge as a function of demand and supply. However, economists also apply equilibratory expectations to markets like the labor market (Rogerson, Shimer, and Wright 2005). While there is nothing wrong with this assumption in principle, making an equilibristic assumption about labor markets can imply, for example, that all unemployed workers are unemployed by choice. ${ }^{3}$ These types of statements sit poorly with sociologists, who are generally interested in social inequality, and motivate sociological critiques of economic assumptions.

\section{ECONOMICS AND SOCIOLOGY: THE BATTLEFRONT}

\section{Sociological Criticisms of Economics}

Sociologists are generally displeased with the economic way of thinking. Most of this displeasure is aimed at the economic assumption of rationality. Some sociologists use rational choice assumptions; in fact, there is a whole ASA section and journal devoted to the approach. However, the majority of sociologists dispute the validity of placing rational constraints on actors (Granovetter 1985; Swedberg and Granovetter 1991). For example, Michel Callon and his students $(1998,2007 ; 2003 ; 2006)$ argue that the enactment of economic models actually brings reality more into line with those principles, rather than economists' claims that their models accurately represent reality. Swedberg and Granovetter (1991) take up a different mode of critique in the introduction to their edited Handbook of Economic Sociology by chastizing economists for reducing social institutions to rational calculations (e.g., Williamson 1981, 1993). In general, sociological criticisms can be summarized into three general shortcomings of economic thinking, and thus economic choice models:

1. Economists omit a suitable, endogenous account of taste creation. (Preference Formation)

2. Economic models preclude individuals from directly affecting each others' utility functions in a given situation. (Social Influence)

3. Economic models have no ability to investigate the effects of socially-constructed phenomena, like attributes and institutions. (Social Constructions)

A point of clarification is in order on the third criticism. As the previous section discussed, economists frequently make group-level predictions. However, in the economic way of thinking, individual actions produce system-level outcomes, but only do so in the aggregate. These system-level outcomes include things like the unemployment rate, the rate of return on investments, or the cost of bottled water. Sociologists recognize these group-level

\footnotetext{
${ }^{3}$ Conditional on the market.
} 
outcomes, but the assumption of sociability introduces an altogether different set of aggregate outcomes, produced from inter-action: social constructions. Social constructions, at least to the individuals who construct them, are greater than the sum of their parts. Common examples are systems of laws or differences in race. These phenomena, despite their ephemerality, are nevertheless "real" to the people who construct them. As such, sociologists often want to model these effects in a way that maintains their socially-constructed nature, rather than as mere aggregates of individual preferences.

An individual choice model will need to resolve all three criticisms in order to be palatable to sociologists. Before describing sociological approaches to these three phenomena, I first address economists' attempts to account for them.

\section{Economists Account for Tastes and Identity}

These shortcomings in the economic approach have not gone unnoticed, and creative economic thinkers have begun attempts to account for them. ${ }^{-1}$ Two notable examples are Gary Becker's Accounting for Tastes (1996) and George Akerlof and Rachel Kranton's identity economics (Akerlof and Kranton 2000, 2010).

Becker (1996) attempts to address criticisms about preference formation and social influence. He incorporates these concepts as additive terms in an individual's utility function, each with its own "capital" concept. The additive term for preference formation (personal capital) stands for an individual's investment in his or her future preferences; an individual does things that he or she thinks will raise his or her future personal capital. The additive term for social influence, social capital, departs from sociological definitions of social capital (Coleman 1988; Lin 2001; Mouw 2003), and instead refers to the margin between an individual's own monetary resources and the montary value that individual recieves from the particular condition or behavior of other actors (Becker 1996, p. 193). In other words, an individual is "influenced" by others in his or her actions, but only insofar as the states of other people affect the monetary utility of that individual (e.g., a father's daughter being healthy and happy).

Akerlof and Kranton describe how individual attributes can be incorporated into individual utility. Their modified utility function includes coefficients for an individual's identified categories, and for social prescriptions about those categories. They argue that individual actions can change categories and prescriptions (Akerlof and Kranton 2000:720), but do not provide an in-depth account of this process, or describe how shifting categories/prescriptions affect individuals (falling victim to sociological criticism \#1). Similarly, they do not provide an account of how an individual's utility function can be directly

\footnotetext{
${ }^{4}$ Whether sociologists hold enough sway to have provoked them is debatable.
} 
affected by another individual's utility function. Their framework allows for game-like behavior where individuals respond to the choices of others, but does not specify any direct correlation in utilities except through general categories and prescriptions. In other words, actors cannot incorporate the views of others in their action, except with respect to their chosen categories and the prevailing prescriptions for those categories.

Each of these approaches offer useful formalizations, some of which bear close resemblance to the model I develop below. However, both fall short of producing a patalable sociological model because they necessarily retain the core economic principles of strategic/rational action and individual utility maximization. We must therefore look elsewhere for a sociological model of individual choice. In a following section, I describe how sociologists have approached and documented their three criticisms of economic thinking.

\section{SOCIOLOGICAL THINKING AND INDIVIDUAL CHOICE}

To quickly recap, sociological distate for the economic approach manifests in three main criticisms: its ignorance of preference formation, its elision of social influence, and its atomization and reduction of social constructions. The root cause of this distate can be summarized quite simply: sociologists assume that motivations for choice are endogenous, while economists assume the motivations for choice are exogenous (Bowles 2001; Dechter 2001; Durlauf 2001; Tao and Winship 2001). In other words, sociological actors are sociable, while economic actors are rational. This section outlines the core principles sociological assumptions about sociability by surveying sociological perspectives on preference formation, social influence, and group outcomes. Each section summarizes extant literature, and draws out the elements necessary for a palatable sociological account of individual choice.

\section{Preference Formation: A French Story}

Contemporary sociology generally proceeds according to a single account of the preference formation process: Pierre Bourdieu's articulation in Distinction (1984). Bourdieu's approach in general (implicitly) integrates earlier class- and status-based accounts (Bowles and Gintis 1976; Blau and Duncan 1978), accounting for preference formation as a combination of the material and social positions into which one is born (i.e. class and socioeconomic status) and one's socialization into the social hierarchy. 5 In concert, these experiences lead individuals to seek goods and services not to satiate their own direct utility, but to maintain and reproduce their position in the structure of social positions. Attempts at reproduction are filtered through the formative environments and experiences of one's childhood, which are more

\footnotetext{
${ }^{5}$ Bourdieu's account varies in its emphases across his anthology, but retains the main structure throughout.
} 
advantageous for some than others (Bourdieu and Passeron 1977; Bourdieu 1990; Bourdieu and Wacquant 1998). Bourdieu eventually argued that straightforwardly economic topics, like housing markets, are nothing but another superficial gloss over the same strategic process (Bourdieu 2005).

Bourdieu's account is somewhat curious, because it places similar constraints to the economic approach on individual cognition (Bourdieu 1977). However, the models' similarity actually serves to highlight Bourdieu's most sociological assumptions: (1) his incorporation of objective and subjective positions into the formation of tastes, and (2) his emphasis on elucidating mechanisms of choice-based social control.6 Class, status and power have motivated sociological analyses since the discipline's initial declarations (Weber 1968; Marx 1993). Their endogenous quality and consequences means these concepts are largely ignored or narrowed by the economic approach. They must be robustly incorporated in any model of individual choice that aspires to be palatable to sociologists.

\section{Social Influence: An Embeddedness Story}

Present in Bourdieu's account, but made more explicit in other work, is the idea of social influence. Social influence means moving beyond economic concepts of monitoring, confirming, and reacting to behaviors, and can be stated in economic terms as the ability of others to directly affect a given individual's utility function (Bowles 2001:90). Granovetter (1985) was the first to formalize this critique, through his concept of "embeddedness." The embeddedness hypothesis claims that behavior, and even economic behavior, is so inextricably limited by ongoing social relations that to construe it as "individual" is a serious mistake (p. 481-482). Embeddedness, and particularly the phrase "ongoing social relations" has proven to be a bit of a slippery concept, and sociologists have depicted forms of social influence that both conform to and critique Granovetter's understanding.

\section{Structural Constraint and Influence}

The program that Granovetter proposes is structural, making social networks the focal constraint on human behavior. Social network analysts view individuals as "nodes," which are "tied" together through their social interactions. Some network analysts retain a rational view of actors, describing networks as social constraints or opportunities for individual or organizational preference maximization (White 1981, 2002; Burt 1982, 1992; Coleman 1988; Lin 2001). These strategies are not useful as sociological altneratives, because they are compatible enough with the economic way of thinking that economists have started to

\footnotetext{
${ }^{6}$ Bourdieu was not naïve to their similarity, even describing his view as an improvement to Becker's exogenous preference models (Bourdieu and Wacquant 1992:25).
} 
adopt them (Ioannides and Loury 2004; Beaman and Magruder 2012; Jackson, RodriguezBarraquer, and Tan 2012).

A second set of analyses investigate the positive, or additive, influence of network structure. Uzzi $(1996,1997,1999)$ demonstrates the benefits of network diversity on firm outcomes. Others, though not explicitly "economic" sociologists, nevertheless demonstrate structural social influence on individual outcomes (Friedkin and Cook 1990; Friedkin 1998; Moody 2001a). The elements capable of being passed through a network are diverse: status (Rossman, Esparza, and Bonacich 2010), behaviors (Christakis and Fowler 2008; Centola 2010), mental illness (Liu et al. 2010), racial identification (Moody 2001b), obesity (Christakis and Fowler 2007), and even consumer choices (DiMaggio and Louch 1998), to name just a few. The passage of status, behaviors, and attributes through networks represents a stark contrast to economics' exogenous approach to preferences and behavior, by arguing that individual attributes and choices are products of their network ties. As such, it represents a stronger concept of sociability than rational-choice network appraoches, and must be integrated into a sociological account of choice.

\section{Ideational Constraint and Influence}

Granovetter's central place in economic sociology is somewhat ironic, as the field is largely comprised of critical responses to his approach (Zelizer 1988; Fligstein 1990; Callon 1998; Krippner 2002; Bourdieu 2005). In place of influential networks, economic sociologists have elaborated a number of alternative suspensions in which individuals are embedded, and by which they are influenced. The alternative moral (Zelizer 1979, 1985, 1994, 2005), political (Fligstein 1996; Fligstein and Dauter 2007; Krippner 2011), ideological (MacKenzie 2003, 2006; Callon 2007) and organizational (Healy 2000, 2004, 2006) environments descendant scholars have proposed for economic behavior can be broadly classified as "institutional" or "cultural" alternatives to social network analysis' structural foundations. In other words, these alternatives generally argue for the influential capacity of socially-constructed ideas, rather than structural coercion (Meyer et al. 1997).

Institutional-cultural embeddedness draws attention to the cultural context of individual behavior. It acknowledges that individuals in similar contexts or similar network positions may have dramatically different utility functions based on their ways of interpreting or evaluating a given situation (Healy 2000; Vaisey 2009; Miles 2015). The institutionalcultural appraoch explains differential choices and outcomes of enterprising actors by referencing their institutional environments and efforts, rather than purely their structural position (Fligstein 1990, 1996). Sociologists have even documented institutional-cultural influence on economists themselves (Fourcade 2009). 
An institutional-cultural view also draws attention to the homogenizing forces of takenfor-granted categories and norms. Within and across organizations, institutionalized categories impel producers, consumers, and critics alike to conform existing categories, because audiences use categories as cognitive eigenvectors to reduce market complexity (Zuckerman 1999, 2004). These categories shape all levels of market behavior from national regulation of market structures (Fligstein 1990; Fourcade Gourinchas and Babb 2002) to organizational outcomes (Ruef 1999, 2000; Turco 2010), to individual-cognitive affect and behavior (Zucker 1977; Correll 2004; Healy 2004; Hallett 2010).

In sum, sociologists have articulated two mechanisms of social influence. Structural thinkers argue that social influence is passed as a function of interactivity and connection patterns in a particular group; the institutional-cultural view assumes that social influence operates not just through concrete network ties, but through the proliferation and enactment of categories, norms, values, beliefs, and roles. The structural view has already been integrated into an individual choice framework (Pescosolido 1992), and any new model must incorporate it as well. Institutional-cultural influences pose a slightly more complicated agenda, because they operate at multiple levels of analysis. For example, individuals can directly share values with one another, but individuals also might feel pressured by a socially-constructed role or identity. The next section addresses the incorporation and measurement of these effects in an aggregate, socially-constructed sense.

\section{Estimating Effects of Social Constructions}

A key consequence of sociability is that interacting individuals produce and internalize generalized phenomena that they use descriptively and proscriptively. These generalized phenomena can be codified as distinct collective identities, like organizations or races, and/or as generalized identities for individuals (roles). These phenomena can be ascribed (given by others) or attained (pursued and achieved). The previous section addressed the the proscriptive use of these generalized phenomena in individual behavior. This section addresses sociologists' frequent desire to reflect the beliefs of their respondents by talking about these generalized phenomena as things in and of themselves.

This is true for structural thinkers like social network analysts, who strive to report network-level outomes (Wasserman and Faust 1994; Moody and White 2003), and for scholars who describe labor-market effects for "blacks" (Pager 2003; Pager, Bonikowski, and Western 2009), "mothers" (Budig and England 2001; Correll, Benard, and Paik 2007; Budig and Hodges 2010) and "immigrants" (Portes and Sensenbrenner 1993). Similarly, whereas economists describe variation in educational outcomes as individual decisions (Schultz 1961; Bedard 2001), even qualitative sociologists are more likely to describe 
grouped educational outcomes as a function of race or socioeconomic status (Lareau 2000, 2002, 2003; c.f., Vaisey 2010).

The economic way of thinking has no way to account for socially-constructed phenomena like these. Even economic institutionalists reduce collective productions to rational cost-saving measures (Williamson 1981, 1993). But this way of viewing the world is so fundamentally a part of sociological thinking that it could serve as the discipline's unifying principle. Obviously, a model of individual choice will need a way to account for these sociallyconstructed "things" in a deep and fundamental way.

\section{Morality as Social Utility}

As should be clear at this point, the sociological way of thinking requires an altogether different concept than rational utility to be maximized in an individual's choice process. I propose that sociologists think of agents as maximizing their own idiosyncratic morality function when they make choices (Etzioni 1988). By morality, I mean two things. First, that the function an individual maximizes is endogenous, or socially-defined. Second, that individuals choose the outcome that subjectively "seems like the most right thing to do" in a given context; maximizing morality simply maximizes situational "reasonability." My emphasis on the context of the situation does not imply that an individual's morality function is completely situationally-defined; it is not. Rather, I am simply acknowledging that, as in economics, the maximal morality of a situation is conditional on the choices being offered. Mathematically:

$$
O=\max \left(M_{i} \mid C\right)
$$

where $\mathrm{O}$ is the chosen option, $M_{i}$ is the individual's morality function, and $C$ is the set of choices in a given situation. This merely formalizes that individuals cannot maximize their morality by choosing things that do not exist, or, importantly, that they do not think are possible. In other words, an individual cannot choose to go to college if she does not think going to college is an option that she can choose.

My use of the word "morality" may conjure up notions of formal, normative standards of behavior governing individual conduct. This understanding of morality is too strong. Rather, I call the latent function individuals maximize their "morality" function, because doing so reinforces that the function is socially-produced and socially-constructed. Whether an individual is socialized to be religious, fascist, Italian, athletic, black, or bureaucratic, that individual merely behaves in a way that seems most right in each situation. Consider Bourdieu's description of action: 
"practical evaluation of the likelihood of the success of a given action in a given situation brings into play a whole body of wisdom, sayings, commonplaces, ethical precepts ('that's not for the likes of us') and, at a deeper level, the unconscious principles of the ethos which, being the product of a learning process dominated by a determinate type of objective regularities, determines 'reasonable' and 'unreasonable' conduct for every agent subjected to those regularities" (Bourdieu 1977:77)

The approach I propose takes this description seriously. This means that the central goal of "theory" and hypothesis generation in sociology should be devoted to producing expectations about the relationship between (1) variables, meaning the things that make individuals different, (2) definitions of "rightness," and, consequently, (3) their effect on probabilities of various outcomes of interest.

For example, do we expect socioeconomic status to lead to different understandings of a college's applicant standards, and thus the probability of college application? Do we expect religious belief to lead to different conceptions of the right way to handle diseases, and thus affect the probability of pursuing treatment? The possibilities are endless, and indirectly occupy the majority of sociological thinking today. The insight of the approach I propose is to focus these questions through individual choice, via the effect different variables have on what individual think is possible and right.

\section{Consequences of Socialibility: Inequality}

What is the long-term systemic expectation of individuals making morality-maximizing choices? The answer is that it depends. Sometimes, the agglomeration of individuals maximizing morality leads to equilibrium or equality (Marx and Engels 1978). More often than not, however, agglomerations of moral choices lead to inequality. I propose that the propensity of moral choices to lead to intragroup inequality at time $t+1$ is a function of two related things in that particular group: (1) the extent of material inequality at time $t$, and (2) the degree of variance in the extant conceptions of morality at time $t$, which is related but not reducible the extent of material inequality.

Examples of morality leading to inequality abound in the sociological literature. For example, Shelly Correll and her coauthors $(2007 ; 2010)$ show that gender norms lead to uneven penalties for working mothers in both hiring decisions and performance evaluations. Pager et al. (2009) show similar patterns for managers hiring low-mage minority and white workers. One can interpret the motivations for these decisions as implicit biases or outright

\footnotetext{
${ }^{7}$ For example, the maximum correlation between household income and any of the choices in the "how decide" question 0.11
} 
collusion, but both interpretations expect individuals to maximize socially-defined "morality" or "reasonableness" of some kind.

Moreover, inequality in both scenarios results from both a prior inequality in circumstances (lower wages and employment for women, lower employment for blacks), and variance in conception of the morality (the reasonableness of blacks and women as workers). The proposed approach recognizes that inequality can even be an unintended consequence of purposive behavior (Merton 1936). In other words, managers may just trying to hire "good" workers, and systematically hire blacks and women less as a consequence. Whether intentional or not, this paper's approach provides clear channels for studying, describing, and reducing inequality by focusing unequal outcomes through the resources and standards of morality (however implicit) employed in individual choices.

Individual morality maximization can have an impact on unequal organizational outcomes as well. For example, Reich (2014) investigates the organizational outcomes of hospitals under new management. He finds that the relationship between the institutional commitments of hospital workers and new hospital management is consequential for the hospital's success; some workers' commitments align with new management's profit-seeking goals, while others outright contradict them, leading to organizational failure. Turco (2012) tells a near-identical story in the case of Motherhood, Inc., a prenatal and children's store aimed at pregnant mothers. Employees' institutionalized identities prevented them from commodifying the process of pregnancy and childbirth, and they refused to sell the company's products. Motherhood, Inc. had a large consumer base, but nonetheless failed due to employee dissent. In both cases, individuals were simply trying to do what seemed like the most "right" or "reasonable" thing to do. The interaction of moral choices with organizational goals is an oft-neglected cause of organizational variance (Selznick 1957, 1996).

\section{Theoretical Conclusion}

The preceding discussion has articulated the baseline standards for sociological models of individual choice. Sociological criticisms of economic assumptions about rationality and preference exogeneity manifest in three distinct properties that must be incorporated into the model: accounting for the endogenous formation of preferences, true incorporation of social influence (both structurally and ideologically), and the formalization and estimation of socially-constructed phenomena. Economic models ultimately fail to integrate these elements in their approach, because they are not derivable from exogenous preferences and rationality. As such, I have proposed that sociologists insist on the sociability of actors, and expect actors to maximize temporally-idiosyncratic, but fundamentally-endogeous, conceptions of the most moral (or "reasonable") thing to do in a particular situation. I turn now to the formalization and implementation of the approach. 


\section{METHODOLOGICAL APPROACH, FORMALIZATION, AND IMPLEMENTATION}

The preceding theoretical discussion implies a particular implementation of choice modeling. This section formalizes the analytical approach. I begin with more general statements about the analytical orientation implied by the approach, and then proceed to more practical statistical implementation.

\section{Conditionality and Context}

The key difference between the approach I advance and previous approaches is in the treatment of analytical conditionality. After all, analytical rigor is nothing more than making as many of an approach's assumptions and conditions as explicit as possible, which allows for more precise hypothesis testing and reproducability.

An important source of conditionality in social scientific studies is the context of the choice being made. The innovation of the economic approach is to assume that actors think and behave in a way that largely ignores context. Thus, the content or area being analyzed becomes significantly less important; claims about actors can apply to all actors, and claims about markets can apply to all markets. However, even economic choices cannot remove the conditionality of the choice on the context of the candidates being offered. As behavioral economists have shown, incorporation of details about even the context of candidates is largely at odds with the economic approach, requiring the incorporating of psychological and sociological insights. Some sociologists have attempted the inverse move, suggesting that actors' behavior is completely constrained by the choice context (Swidler 1986, 2003). The opposite problem to economics plagues this strategy, because individuals seem quite good at patterning action across contexts, and are capable of choosing different contexts altogether (Vaisey 2009).

I instead suggest that sociologists take a third approach to context, by making their analyses and results explicitly conditional on the context. Context in this sense recognizes that the analysis itself is dependent on the data collection strategy, the respondents from whom data were collected, the variables chosen and the coding scheme used, the analytical approach taken, the period in time, the outcome of interest, and any other aspect of the study that might lead to variation in outcomes. For example, a study that makes nationallyrepresentative claims should use nationally-representative samples of respondents. Even nationally-representative studies are limited to inference about a particular country, and likely a particular time period in which the data are measured. Studies should be clear about these kinds of contexts, so that they can be incorporated in future work.

Making these conditionalities explicit encourages sociologists to pursue analytical strategies that address as many of these conditions as possible (i.e. robustness checks). It 
also allows for significant flexibility in choice modeling, because it allows scholars to place bounds on the infinite regress of potential confounding variables. In this framework, critical "what about $x$ ?"-style questions can either be answered by the data, or become projects for future investigation. 8

Most sociological outlets recognize this conditionality by requiring authors to describe the steps they took in their analyses. However, the editorial process often pressures authors to make general claims from their conditional analyses. This pressure is especially curious, because it runs directly counter to the core insight of sociology, which is that social life is always contingent. Status, race, gender, and all of their derivative sociological concepts are all assumed to be socially-constructed, and thus contingent on those constructing them. The approach in this paper merely formalizes these assumptions into the analytical approach.

By making results conditional on the context, the proposed approach can get by with only two assumptions about all actors:

1. Social actors do what seems like the "best" or "most right" or "moral" thing to do in a given context, to the best of their ability.

2. What seems like the "best" or "most right" or "moral" thing to do in a context is a product of their personal histories, their social influences, and their material resources.

I turn now to the formal implementation of these ideas.

\section{Formal Implementation Preliminaries}

Before discussing the mathematical equations, I want to make two points of clarification about the approach. First, I assume that quantitative analysts will work within the Bayesian tradition of statistical analysis (Lynch 2007; Gelman et al. 2014).9 The simplicitly of economic assumptions is partially due to the sophistication of the statistical models available at the time. In this regard, sociology has benefitted from waiting to develop its own model. The Bayesian approach to data analysis provides an ideal environment for a sociological model of individual choice, because its key difference from standard or frequentist approaches is that Bayesian assume probability is necessarily conditional. This means that there is no "true" effect of race on wages, but instead an estimated range of an effect conditional on the data collected. By sacrificing the assumption of fixed probabilities, sociologists gain an approach that is neatly compatible with their assumptions.

\footnotetext{
${ }^{8}$ Seasoned conference presenters may see this as my approach's primary advantage.

${ }^{9}$ Qualitative work is completely compatible with the approach, but has the decided advantage of being able to investigate choice processes directly, and already openly recognizes its analytical constraints. As such, I focus on quantitative implementation.
} 
Second, I assume that choice is best thought of as a discrete process. The chances for individuals to "partially choose," or to choose some truly continuous value of something are rare. Moreover, sociologists are usually interested in discrete outcomes, like whether an individual attends college or becomes incarcerated. For this reason, I focus on methods for analysis of discrete outcomes. The assumption here is that coefficients affect individuals latent, relative probabilities of doing something, compared to other values of that coefficient. This assumption makes actual statistical estimation much easier (Imai and Van Dyk 2005).

Finally, I emphasize that the approach articulated here is an ideal type. The real-world limitations on data collection and analysis prevent a perfect implementation of the formalized approach. The hope is that analysts will attempt to implement the proposed ideas as closely as possible, and treat limitations as conditions to be explicitly stated when presenting results. Over time, testing of and expansion on conditional claims will move closer to the ideal-typical limit presented below.

\section{Formalization}

Economic approaches begin with an individual's utility function, and so I do the same:

$$
u_{i t}=\max \left(U_{i t} \mid y\right)
$$

which says that an individual's chosen outcome in a situation at time $t\left(u_{i t}\right)$ is the choice from the set of options $y$ one that maximizes his or her utility function $U_{i t}$. I propose the following decomposition of $U_{i t}$ :

$$
U_{i t}=V_{i t}+S_{i t}+R_{i t}\left(+G_{i}\right)
$$

where $V_{i t}$ are variables representing a person's particular preferences (values) at time $t$, $S_{i t}$ are variables representing the social influence of others, and $R_{i t}$ represents an individual's material resources. As in economic models, this utility decomposition can be neatly integrated into a regression modeling framework. Datasets with genetic markers can add a fourth term, $G_{i}$ to control for any genetic variation in outcomes (see Freese (2008)). Logit and probit regression models set the probability of an outcome equal to a transformed set of observed covariates:

$$
P\left(y_{i}=1\right)=\lambda\left(X_{i} \beta\right)
$$

where $\lambda$ is the link function, $\beta$ is a vector of coefficient terms, $X_{i}$ is the observed covariates for individual $i$, and $y_{i}$ is the observed binomial outcome for individual $i$. We can modify this equation to include the proposed covariates as follows: 


$$
P\left(y_{i t}=1\right)=\lambda\left(X_{i}\left(V_{i t}+S_{i t}+R_{i t}\right)\right)
$$

with priors:10

$$
\begin{gathered}
V_{i t} \sim N\left(\hat{S}_{i t-}+\hat{R}_{i t-}, \frac{r \cdot v \cdot\left(\hat{S}_{i t-}+\hat{R}_{i t-}\right)}{T}\right) \text { for cases where } V_{n t}=V_{i t} \text { over } N \\
\left.S_{i t} \sim N\left(\hat{S}_{i t-}\right), \frac{r \cdot v \cdot\left(\hat{S}_{i t-}\right)}{T}\right) \text { for cases where } S_{n t}=S_{i t} \text { over } N \\
\left.R_{i t} \sim N\left(\hat{R}_{i t-}\right), \frac{r \cdot v \cdot\left(\hat{R}_{i t-}\right)}{T}\right) \text { for cases where } R_{n t}=R_{i t} \text { over } N
\end{gathered}
$$

There are a few important features of these priors. First, the prior for $V_{i t}$ does not include past measures of $V_{i}$. This means that an individual's values at time $t$ are themselves direct products of their social influences and material resources in previous time periods $(t-)$. I specify the prior this way for two reasons. First, a fully Bayesian approach also specifies a prior on the likelihood; this accounts for past choices by the individual, and accounts for past preferences those choices are assumed to maximize. Second, this framework merely formalizes the sociological assumption that individual preferences are wholly exogenous (e.g. Blau and Duncan 1978). As individuals progress, the coefficient for $V_{i t}$ becomes more idiosyncratic. Nevertheless, I assume this value varies similarly across individuals with similar social influence and material resource histories, in accordance with prior work (Berger and Luckmann 1966:50; Bourdieu 1984). Formally, this is represented by a normal prior on coefficients for $V_{i t}$ with mean $\mu\left(S_{i t-}+R_{i t-}\right)$ and variance $r . v .\left(S_{i t-}+R_{i t-}\right) / T$ where $T$ is the number of prior time-observations for $S$ and $R$, and r.v. stands for residual variance. Constraints on data collection mean these measures will likely not be available. In those situations, past direct measures of $V_{i}$ are perfectly suitable replacements. For example, the National Study of Youth and Religion asks teens about their moral metrics for deciding what to do in ambiguous situations, but it does not ask their friends or parents this question. Thus, we can use past measures of this variable as priors for $V_{i t}$.

It is also important to note that the coefficient priors are calculated using past effect sizes and residual variances of the observed variables for all individuals who match a given individual on the set of attributes. So, the prior on individuals with a college degree and middleclass parents at time $t$ uses past effect sizes and residual variances of education and parents'

\footnotetext{
${ }^{10} G_{i}$ is constant, and thus has a flat-normal prior.
} 
SES on the dependent variable for all individuals with a college degree and middle-class parents at time $t$. Insofar as these measures are consistent over time, the variance of the prior is reduced, and it becomes more influential in predicting the outcome.

In sum, these priors flexibility model both the ability of terms to change with new experiences, and also the relative stability provided by constant social and material influences over a life course. Together, the outline proposed in this section incorporates true preference endogeneity, while still accounting for individual variance across time. The model simultaneously incorporates the sociological insight that individual preferences tend to cluster along particular axes, and models outcomes using past effects of similar individuals along those axes.

\section{Measuring Material Context}

There are no a priori constraints on measurements of material context, so long as the relationship between a variable and the probability of an outcome is clearly specified or hypothesized. For example, we would expect an increase in education to increase an individual's probability of voting for a Democratic political candidate, or of liking jazz music.

$R_{i t}$ can be further analytically decomposed into $R_{w}$ and $R_{p}$, which measure an individual's actual and perceived material resource conditions, respectively. This takes into account the fact that individuals can be limited by both: an individual who only has $\$ 5$ cannot enter a $\$ 10$ movie, and an individual who has enough money to attend college may not because she believes she does not have enough to do so. This helps to account for psychological manipulations where so-called "framing" of a monetary or other outcome affects people's decisions (Tversky and Kahneman 1981). $R_{w}$ and $R_{p}$ are likly correlated, but this is an empirical question. In cases where they are correlated, analysts can use $R_{p}$ as an instrument for $R_{w}$ on the dependent variable. This is because (1) in the limit, the correlation between these variables is 1 , and $R_{w}==R_{p}$, and (2) $R_{w}$ is not likely to have effects independent of $R_{p}$.

\section{Measuring Social Context}

Measuring social context is similarly agnostic to measurement, excepting that one must use the regression approach. Nevertheless, measuring social influence as structural properties of a relationship (its duration, physical copresence, etc.) is completely compatible with my approach, so long as there is some hypothesized linear relationship between the variable and probabilities of the outcome. Though it is worth noting, as in the material resources context, that respondent beliefs and attitudes likely completely mediate the effect of structural conditions (Lizardo 2006; Vaisey and Lizardo 2010). 
In addition, $S_{i t}$ can be further decomposed into measures alters' perceptions/preferences for ego, $S_{a}$, and ego's perceptions/preferences for alters, $S_{e}$. Thus, it may make sense to include a manager's $S_{a}$ about individual $i$ 's race in the equation for his or her propensity to offer an individual a job, but may not make sense to include an individual's $S_{e}$ about their own race, unless it relates to their probability of applying for or accepting a job. Instead, we might include the applicant's preference for working with individuals of the same race, or alters' expectations for the applicant as they relate to the particular job.

\section{Modeling Interdependency}

The previous section elaborated a formal approach to directly incorporating the known preferences or choices of others. However, it did not address situations where the probabilities of an outcome is a function of multiple utility functions. A clear example of this situation is the hiring process. Let's say we want to predict whether or not an individual will be hired. There are three discrete probabilities involved:

1. an individual $i$, applies for a job $j$ with probability $p_{i j}$, which is conditional on the set of job openings and his or her morality function

2. the hiring manager offers a job to the individual with probability $p_{h i}$ conditional on his or her morality function and the set of candidates

3. the individual accepts the job with probability $p_{a i j}$, conditional on being offered the job $\left(p_{h i}\right)$, the set of other offers, and their own morality function

The probability that individual $i$ accepts job $j$ is thus the joint probability $\mathrm{P}\left(p_{i j}, p_{h i}, p_{a i j}\right)$. There are a number of ways to model these outcomes, using both linear regression techniques like Seemingly Unrelated Regressions (Zellner and Ando 2010), or using agent-based modeling. Agent-based modeling has recently gained traction in sociology, but it is (somewhat curiously) most often used to model structural outcomes (Hedström 2005; Watts 2014; DellaPosta, Shi Yongren, and Macy 2015). The fundamental insight of agent-based models is that they allow analysts to examine the effects of individual choices, and as such are excellent companions to the proposed approach.

\section{Modeling Attributive, Historical and Organizational Context}

I have sketched methods for incorporating influences from preferential, social, and resource contexts in sociological models of individual decision-making. This final section addresses socially-constructed contexts beyond the level of the individual: attributive contexts, historical contexts, and organizational contexts. 
Each of these contexts is modeled the same way: as hierarchical terms in the model. Historical and organizational contexts fit neatly into this framework, as they are already modeled this way (Raudenbush and Bryk 2001; Yang and Land 2013). But why am I suggesting we model attributive contexts as hierarchical terms? The reasons for this are simple: individuals participate in or embody socially-constructed attributes in an identical manner to the way they participate in or embody organizations or historical cohorts. Individual preferences, social influences, and resources vary across social attributes, and the effects of attributes vary across contexts.

To illustrate, let us consider gender; sociologists assume that gender is a sociallyconstructed concept distinct from sex. Though sociologists usually use gender as an individual-level predictor, its effects are more accurately hierarchical. Individual preferences, social influences, and resources may cluster by gender, as they do by birth cohort, but also vary across and within gender. For example, we might expect the relationship of a preference for having a family on career choices to vary across genders (Blair-Loy 2005, 2010; Cech et al. 2011).

Modeling socially-constructed attributes in this way provides a closer approximation of sociological thinking about socially-constructed categories than interaction effects, because it allows for an easier incorporation of multiple gendered effects simultaneously through varying intercepts. Thus, we can examine the interaction effects of family preferences and material resources for women and men simultaneously, while also deriving attribute-level effects for men and women. This approach also enables a more valid implementation of intersectionality, which is the study of outcomes across membership in multiple attributive categories. Multiple membership models, which allow analysts to specify weights of various random effects, nicely formalize this approach and has the added benefit of making explicit analysts' assumptions about the relative importance of various attributes (Browne, Goldstein, and Rasbash 2001).

\section{Methodological Conclusion}

The methodological discussion in this section only sketches applications of the approach. Actual particularities of implementation will require testing and amendment with actual data. To this end, the analytical approach to context and the formalization of endogenous preferences serve as guiding principles to these endeavors. In this way, sociological investigation of choices can build on itself, and produce a robust body of fine-grained knowledge akin to economics. 


\section{CONCLUSION}

Sociology is approaching a crossroads; the increasing volume of calls for analytical rigor are difficult to ignore (Hedström and Bearman 2009). Economic sociology is itself at a point of transition, openly wondering whether Granovetter's "embeddedness" should still unify investigations (Krippner 2002; Krippner and Alvarez 2007; Bandelj 2012; Zelizer 2012). We must be careful not to dispense with baseline sociological assumption in the development of analytical rigor, and to recognize that analytical rigor is mutually exclusive to piecemeal, superficially-integrative solutions.

This paper advocates an approach rooted in the choices of sociable individuals. In doing so it echoes long-standing, but temporarily-displaced suggestions for the discipline (Parsons and Shils 1951), but departs from the approaches taken by many contemporary sociologists. Given the strong analytical approach of economics, and the analytical formalism of Granovetter's seminal structural suggestion, it makes sense for the approach to take hold first in economic sociology. At present, most economic sociologists since Granovetter have avoided serious interaction with economics, instead attending to the economy as a topic. This paper is one attempt to answer Granovetter's call for sociologists to egage with economics at its foundation: the analysis of social action.

\section{REFERENCES}

Akerlof, George A., and Rachel Kranton. 2010. Identity Economics: How Our Identities Affect Our Work, Wages, and Well-being. Princeton, NJ: Princeton University Press.

Akerlof, George A., and Rachel E. Kranton. 2000. “Economics and Identity.” The Quarterly Journal of Economics 115(3):715-53.

Ariely, Dan. 2008. Predictably Irrational. New York, NY: HarperCollins.

Bandelj, Nina. 2012. “Relational Work and Economic Sociology.” Politics $\{\mho\}\}$ Society 40(2):175-201.

Beaman, Lori, and Jeremy Magruder. 2012. "Who Gets the Job Referral? Evidence From a Social Networks Experiment.” The American Economic Review 102(7):3574-93.

Becker, Gary S. 1993. "Nobel Lecture: The Economic Way of Looking at Behavior.” Journal of Political Economy 101(3):385-409.

Becker, Gary S. 1996. Accounting for Tastes. Cambridge, MA: Harvard University Press.

Bedard, Kelly. 2001. "Human Capital Versus Signaling Models: University Access and High 
School Dropouts." Journal of Political Economy 109(4):749-75.

Benard, S., and S. J. Correll. 2010. "Normative Discrimination and the Motherhood Penalty." Gender $\{\mho\}\}$ Society 24(5):616-46.

Berger, Peter L., and Thomas Luckmann. 1966. The Social Construction of Reality. Anchor Books.

Blair-Loy, Mary. 2005. Competing Devotions: Career and Family Among Women Executives. Cambridge, MA: Harvard University Press.

Blair-Loy, Mary. 2010. "Moral Dimensions of the Work-Family Nexus." in Handbook of the sociology of morality, edited by Steven Hitlin and Stephen Vaisey. Springer.

Blau, Peter M., and O. D. Duncan. 1978. American Occupational Structure. 1st ed. Free Press.

Bourdieu, Pierre. 1977. Outline of a Theory of Practice. Cambridge University Press.

Bourdieu, Pierre. 1984. Distinction: A Social Critique of the Judgement of Taste. Harvard.

Bourdieu, Pierre. 1990. Homo Academicus. Stanford.

Bourdieu, Pierre. 2005. The Social Structures of the Economy. Polity.

Bourdieu, Pierre, and Jean-Claude Passeron. 1977. Reproduction in Education, Society and Culture. Sage.

Bourdieu, Pierre, and Loïc Wacquant. 1992. An Invitation to Reflexive Sociology. University Of Chicago Press.

Bourdieu, Pierre, and Loïc Wacquant. 1998. The State Nobility: Elite Schools in the Field of Power. Palo Alto, CA: Stanford University Press.

Bowles, Samuel. 2001. "Comment: individual behavior and social interactions.” Sociological Methodology 31:89-96.

Bowles, Samuel, and Herbert Gintis. 1976. Schooling in Capitalist America: Educational Reform and the Contradictions of Economic Life. Basic Books.

Browne, W.J., H. Goldstein, and J. Rasbash. 2001. "Multiple membership multiple classification (MMMC) models.” Statistical Modelling 1(2):103-24.

Budig, Michelle J., and Paula England. 2001. “The Wage Penalty for Motherhood.” Ameri- 
can Sociological Review 66(2):204-25.

Budig, Michelle J., and Melissa J. Hodges. 2010. "Differences in Disadvantage: Variation in the Motherhood Penalty Across White Women's Earnings Distribution.” American Sociological Review 75(5):705-28.

Burt, Ronald S. 1982. Toward a Structural Theory of Action : Network Models of Social Structure, Perception, and Action. New York : Academic Press.

Burt, Ronald S. 1992. Structural Holes: The Social Structure of Competition. Harvard University Press.

Callon, Michel. 1998. “The Embeddedness of Economic Markets in Economics.” in The laws of the market, edited by Michel Callon. Sociological Review Monograph.

Callon, Michel. 2007. "What Does It Mean to Say That Economics Is Performative?" Do Economists Make Markets?: On the Performativity of Economics 311-57.

Cech, Erin, Brian Rubineau, Susan Silbey, and Caroll Seron. 2011. "Professional Role Confidence and Gendered Persistence in Engineering." American Sociological Review 76(5):641-66.

Centola, Damon. 2010. “The Spread of Behavior in an Online Social Network Experiment." Science 329(5996):1194-7.

Christakis, Nicholas A., and James H. Fowler. 2007. "The Spread of Obesity in a Large Social Network Over 32 Years." New England Journal of Medicine 357:370-79.

Christakis, Nicholas A., and James H. Fowler. 2008. “The Collective Dynamics of Smoking in a Large Social Network." New England Journal of Medicine 358:2249-58.

Coleman, James S. 1988. "Social Capital in the Creation of Human Capital."

Correll, Shelley J. 2004. "Constraints Into Preferences: Gender, Status, and Emerging Career Aspirations.” American Sociological Review 69(1):93-113.

Correll, Shelley J., Stephen Benard, and In Paik. 2007. "Getting a Job: Is There a Motherhood Penalty?” American Journal of Sociology 112(5):1297-1339.

Dechter, Aimée R. 2001. "Comment: potential applications and extensions for a binary choice-based social interaction framework.” Sociological Methodology 31(1):107-21.

DellaPosta, Daniel, Shi Yongren, and Michael Macy. 2015. “Why Do Liberals Drink Lattes?” 
American Journal of Sociology 120(5):1473-1511.

DiMaggio, Paul. 1988. "Interest and agency in institutional theory." in Institutional patterns and organizations: Culture and environment. Cambridge, MA: Ballinger.

DiMaggio, Paul, and Hugh Louch. 1998. "Socially Embedded Consumer Transactions: For What Kinds of Purchases Do People Most Often use Networks?” American Sociological Review 63(5):619.

Domencich, Tom, and Daniel L. McFadden. 1975. Urban Travel Demand: A Behavioral Analysis. New York, NY: North-Holland/American Elsevier Publishing.

Durlauf, Steven N. 2001. "A Framework For The Study of Individual Behavior and Social Interactions." Sociological Methodology 31(1):47-87.

Etzioni, Amitai. 1988. The Moral Dimension: Toward a New Economics. New York, NY: Free Press.

Fligstein, Neil. 1990. The Transformation of Corporate Control. Cambridge, MA: Harvard University Press.

Fligstein, Neil. 1996. "Markets as Politics: A Political-Cultural Approach to Market Institutions." American Sociological Review 61(4):656-73.

Fligstein, Neil, and Luke Dauter. 2007. “The Sociology of Markets.” Annual Review of Sociology 33(1):105-28.

Fourcade Gourinchas, Marion, and Sarah L. Babb. 2002. "The Rebirth of the Liberal Creed: Paths to Neoliberalism in Four Countries." American Journal of Sociology 108(3):533-79.

Fourcade, Marion. 2009. Economists and Societies: Discipline and Profession in the United States, Britain and France, 1890s-1990s. Princeton, NJ: Princeton University Press.

Freese, Jeremy. 2008. "Genetics and the Social Science Explanation of Individual Outcomes." American Journal of Sociology 114(S1):S1--S35.

Friedkin, Noah E. 1998. A Structural Theory of Social Influence. Cambridge University Press.

Friedkin, Noah E., and Karen S. Cook. 1990. "Peer Group Influence.” Sociological Methods $\{\mho \mho\}$ Research 19(1):122-43.

Gelman, Andrew et al. 2014. Bayesian Data Analysis. Boca Raton, FL: CRC Press.

Granovetter, Mark. 1985. “Economic Action and Social Structure: The Problem of Embed- 
dedness." American Journal of Sociology 91:788-89.

Hallett, T. 2010. “The Myth Incarnate: Recoupling Processes, Turmoil, and Inhabited Institutions in an Urban Elementary School.” American Sociological Review 75(1):52-74.

Healy, Kieran. 2000. "Embedded Altruism: Blood Collection Regimes and the European Union's Donor Population.” American Journal of Sociology 105(6):1633-57.

Healy, Kieran. 2004. "Altruism as an Organizational Problem: The Case of Organ Procurement." American Sociological Review 69(3):387.

Healy, Kieran. 2006. Last Best Gifts: Altruism and the Market for Human Blood and Organs. Chicago, IL: University Of Chicago Press.

Hedström, Peter. 2005. Dissecting the Social: On the Principles of Analytical Sociology. Cambridge: Cambridge University Press.

Hedström, Peter, and Peter Bearman. 2009. The Oxford Handbook of Analytical Sociology. Oxford University Press, USA.

Hough, Douglas E. 2013. Irrationality in Health Care: What Behavioral Economics Reveals About What We Do and Why. Palo Alto, CA: Stanford University Press.

Imai, Kosuke, and David a. Van Dyk. 2005. "A Bayesian analysis of the multinomial probit model using marginal data augmentation." Journal of Econometrics 124(2):311-34.

Ioannides, Yannis M., and Linda Datcher Loury. 2004. "Job Information Networks, Neighborhood Effects, and Inequality.” Journal of Economic Literature 42(4):1056-93.

Jackson, Matthew O., Tomas Rodriguez-Barraquer, and Xu Tan. 2012. "Social Capital and Social Quilts: Network Patterns of Favor Exchange." The American Economic Review 102(5):1857-97.

Just, David R., and Collin R. Payne. 2009. “Obesity: Can behavioral economics help?” 38.

Kahneman, Daniel, Jack L. Knetsch, and Richard H. Thaler. 1991. "Anomalies: The Endowment Effect, Loss Aversion, and Status Quo Bias." Journal of Economic Perspectives 5(1):193-206.

Krippner, Greta R. 2002. "The Elusive Market: Embeddedness and the Paradigm of Economic Sociology." Theory and society 30(6):775-810.

Krippner, Greta R. 2011. Capitalizing on Crisis: The Political Origins of the Rise of Finance. 
Harvard University Press.

Krippner, Greta R., and Anthony S. Alvarez. 2007. "Embeddedness and the Intellectual Projects of Economic Sociology.” Annual Review Sociology 33:219-40.

Lareau, Annette. 2000. "Home Advantage: Social Class and Parental Intervention in Elementary Education."

Lareau, Annette. 2002. "Invisible Inequality: Social Class and Childrearing in Black Families and White Families.” American Sociological Review 67(3):747-76.

Lareau, Annette. 2003. Unequal Childhoods: Race, Class, and Family Life. California.

Lin, Nan. 2001. Social Capital: A Throry of Social Structure and Action. Cambridge UP.

Liu, Ka-Yuet, Marissa King, and Peter S. Bearman. 2010. "Social influence and the autism epidemic.” American Journal of Sociology 115(5):1387-1434.

Lizardo, Omar. 2006. "How Cultural Tastes Shape Personal Networks.” American Sociological Review 171(5):778-807.

Lynch, Scott. 2007. Introduction to Applied Bayesian Statistics and Estimation for Social Scientists. Springer; 1 edition (July 27, 2007).

MacKenzie, Donald. 2003. "Long-Term Capital Management and the Sociology of Arbitrage." Economy and Society 32(3):349-80.

MacKenzie, Donald. 2006. An Engine, Not a Camera: How Financial Models Shape Markets. MIT Press.

MacKenzie, Donald, and Yuval Millo. 2003. "Constructing a Market, Performing Theory: The Historical Sociology of a Financial Derivatives Exchange." American Journal of Sociology 109(1):107-45.

Marx, Karl. 1993. Capital. Penguin Classic.

Marx, Karl, and Friedrich Engels. 1978. “The Communist Manifesto.” in The marx-engels reader, edited by Robert $C$ Tucker. Norton.

Merton, Robert K. 1936. “The Unanticipated Consequences of Purposive Social Action." American Sociological Review 1(6):894-904.

Meyer, John W., John Boli, George M. Thomas, and Francisco O. Ramirez. 1997. "World 
Society and the Nation[State." American Journal of Sociology 103(1):144-81.

Miles, Andrew. 2015. "The (Re)genesis of Values: Examining the Importance of Values for Action." American Sociological Review 80(4):680-704.

Moody, James. 2001a. "Peer Influence Groups: Identifying Dense Clusters in Large Networks." Social Networks 23(4):261-83.

Moody, James. 2001b. “Race, School Integration, and Friendship Segregation in America." 107:679-716.

Moody, James, and Douglas R. White. 2003. "Structural Cohesion and Embeddedness: A Hierarchical Concept of Social Groups.” American Sociological Review 68(1):103-27.

Mouw, Ted. 2003. “Social Capital and Finding a Job: Do Contacts Matter?” American Sociological Review 68(6):868-98.

Pager, Devah. 2003. “The Mark of a Criminal Record.” American Journal of Sociology 108(5):937-75.

Pager, Devah, Bart Bonikowski, and Bruce Western. 2009. "Discrimination in a Low-Wage Labor Market: A Field Experiment.” American Sociological Review 74(5):777-99.

Parsons, Talcott, and Edward Shils, eds. 1951. Toward a General Theory of Action: Theoretical Foundations for the Social Sciences. Cambridge, MA: Harvard University Press.

Pescosolido, Bernice A. 1992. "Beyond Rational Choice: The Social Dynamics of How People Seek Help.” American Journal of Sociology 97(4):1096-1138.

Portes, Alejandro, and Julia Sensenbrenner. 1993. "Embeddedness and Immigration: Notes on the Social Determinants of Economic Action." American Journal of Sociology 98(6):1320-50.

Powell, Walter W., and Paul DiMaggio, eds. 1991. The New Institutionalism in Organizational Analysis. University Of Chicago Press.

Raudenbush, Stephen W., and Anthony S. Bryk. 2001. "Hierarchical Linear Models: Applications and Data Analysis Methods."

Reich, Adam D. 2014. "Contradictions in the Commodification of Hospital Care." American Journal of Sociology 119(6):1576-1628.

Rogerson, Richard, Robert Shimer, and Randall Wright. 2005. "Search-Theoretic Models 
of the Labor Market: A Survey.” Journal of Economic Literature 43(4):959-88.

Rossman, G., N. Esparza, and P. Bonacich. 2010. "I'd Like to Thank the Academy, Team Spillovers, and Network Centrality.” American Sociological Review 75(1):31-51.

Rubinstein, Ariel. 2012. Lecture Notes in Microeconomic Theory. Princeton University Press.

Ruef, Martin. 1999. "Social ontology and the dynamics of organizational forms: Creating market actors in the healthcare field, 1966-1994." Social Forces 77(4):1403-32.

Ruef, Martin. 2000. “The Emergence of Organizational Forms: A Community Ecology Approach.” American Journal of Sociology 106(3):658-714.

Schultz, Theodore W. 1961. "Investment in Human Capital." The American Economic Review $1-17$.

Selznick, Philip. 1957. Leadership in Administration: a Sociological Interpretation. Row, Peterson.

Selznick, Philip. 1996. “Institutionalism and 'Old' and 'New'.” Administrative Science Quarterly 41:270-77.

Stigler, George J., and Gary S. Becker. 1977. “De Gustibus Non Est Disputandum.” The American Economic Review 67(2):76-90.

Swedberg, Richard, and Mark Granovetter. 1991. The Sociology of Economic Life. Boulder, CO: Westview Press.

Swidler, Ann. 1986. "Culture in Action: Symbols and Strategies." American Sociological Review 51(2):273-86.

Swidler, Ann. 2003. Talk of Love: How Culture Matters. University of Chicago Press.

Tao, Lin, and Christopher Winship. 2001. "Comment: modelling social interdependence: is it in the structure or in our hearts?” Sociological Methodology 31(1):97-106.

Turco, C. J. 2010. "Cultural Foundations of Tokenism: Evidence From the Leveraged Buyout Industry.” American Sociological Review 75(6):894-913.

Turco, Catherine. 2012. "Difficult Decoupling: Employee Resistance to the Commercialization of Personal Settings.” American Journal of Sociology 118(2):380-419.

Tversky, A., and D. Kahneman. 1981. “The Framing of Decisions and the Psychology of 
Choice." Science 211(4481):453-58.

Uzzi, Brian. 1996. "The Sources and Consequences of Embeddedness for the Economic Performance of Organizations: The Network Effect." American Sociological Review 61(4):674-98.

Uzzi, Brian. 1997. "Social Structure and Competition in Interfirm Networks: The Paradox of Embeddedness." Administrative Science Quarterly 42(1):35-67.

Uzzi, Brian. 1999. "Embeddedness in the Making of Financial Capital: How Social Relations and Networks Benefit Firms Seeking Financing." American Sociological Review 481-505.

Vaisey, Stephen. 2009. "Motivation and Justification: A Dual-Process Model of Culture in Action." American Journal of Sociology 114(6):1675-1715.

Vaisey, Stephen. 2010. "What People Want: Rethinking Poverty, Culture, and Educational Attainment." The ANNALS of the American Academy of Political and Social Science 629(1):75-101.

Vaisey, Stephen, and Omar Lizardo. 2010. "Can Cultural Worldviews Influence Network Composition?” Social Forces 88(4):1595-1618.

Wasserman, Stanley, and Katherine Faust. 1994. Social Network Analysis. Cambridge.

Watts, Duncan J. 2014. “Common Sense and Sociological Explanations.” American Journal of Sociology 120(2):313-51.

Weber, Max. 1968. Economy and Society: An Outline of Interpretive Sociology. edited by Guenther Roth and Claus Wittich. Bedminster.

White, Harrison C. 1981. “Where Do Markets Come From?” American Journal of Sociology 517-47.

White, Harrison C. 2002. Markets From Networks: Socioeconomic Models of Production. Princeton University Press.

Williamson, Oliver E. 1981. "The Economics of Organization: The Transaction Cost Approach." American Journal of Sociology 87(3):548-77.

Williamson, Oliver E. 1993. "Calculativeness, Trust, and Economic Organization.” Journal of Law and Economics 36(1):453-86.

Yang, Yang, and Kenneth C. Land. 2013. Age-Period-Cohort Analysis. Boca Raton, FL: CRC 
Press.

Zelizer, Viviana. 1979. Morals and Markets: The Development of Life Insurance in the United States. Transaction Publishers.

Zelizer, Viviana. 1985. Pricing the Priceless Child: The Changing Social Value of Children. Princeton University Press.

Zelizer, Viviana. 1988. "Beyond the Polemics on the Market: Establishing a Theoretical and Empirical Agenda." 3(4):614-34.

Zelizer, Viviana. 1994. The Social Meaning of Money: Pin Money, Paychecks, Poor Relief, and Other Currencies. Princeton University Press.

Zelizer, Viviana. 2005. The Purchase of Intimacy. Princeton University Press.

Zelizer, Viviana. 2012. "How I Became a Relational Economic Sociologist and What Does That Mean?" Politics $\{\mho \mho\}$ Society 40(2):145-74.

Zellner, Arnold, and Tomohiro Ando. 2010. "A direct Monte Carlo approach for Bayesian analysis of the seemingly unrelated regression model." Journal of Econometrics 159(1):3345.

Zucker, Lynne G. 1977. “The Role of Institutionalization in Cultural Persistence.” American Sociological Review 42(5):726-43.

Zuckerman, Ezra W.1999. “The Categorical Imperative: Securities Analysts and the Illegitimacy Discount." American Journal of Sociology 104(5):1398-1438.

Zuckerman, Ezra W. 2004. "Structural Incoherence and Stock Market Activity." American Sociological Review 69(3):405-32. 